


\title{
SEGUNDA SEMANA DE LA DIVERSIDAD LINGÜÍSTICA DE COSTA RICA: SUS OBJETIVOS Y SUS ACTIVIDADES
}

\author{
SECOND WEEK OF LANGUAGE DIVERSITY IN COSTA RICA: ITS \\ GOALS AND ACTIVITIES
}

\section{Carlos Sánchez Avendaño}

A inicios del 2011 se nos ocurrió organizar por primera vez el evento que en noviembre del 2013 inauguramos en su segunda edición. No sabíamos cómo sería recibido ni cuáles actividades serían las más gustadas, pero estábamos seguros de que queríamos abrir las puertas de nuestra casa e invitar a pasar a tantas personas como nos fuera posible a deleitarse con una de las pasiones que han acompañado por décadas a muchos de los que formamos parte del Departamento de Lingüística: la diversidad y el patrimonio lingüístico de Costa Rica.

El éxito de nuestra propuesta nos motivó a pensar en convertir la iniciativa en un evento regular. En noviembre del 2013 intentamos honrar nuestro compromiso, con la esperanza de que año tras año el proyecto de la Semana de la diversidad lingüística de Costa Rica crezca y, eventualmente, se logre extender a actividades en todo el país.

En su segunda edición, la Semana estuvo organizada en dos unidades temáticas correspondientes a dos objetivos. En primer lugar, deseábamos destacar el papel de la Universidad en lo relativo a la documentación, salvaguarda, investigación y promoción de la diversidad y el patrimonio lingüístico costarricense, para lo cual dedicamos el día lunes 4 de noviembre. En segundo lugar, al igual que hacía dos años, nos movía la convicción de que resultaba fundamental la labor de divulgación acerca de la diversidad y el patrimonio lingüístico de Costa Rica, con el fin de que todos aprendamos a reconocer, respetar y apreciar la enorme riqueza contenida en las lenguas y en las artes verbales de nuestro país. Desde el martes 5 y hasta el viernes 8 de noviembre procuramos cumplir con este segundo objetivo.

En lo que respecta al primer objetivo, queríamos destacar que la Universidad de Costa Rica viene cumpliendo a cabalidad desde hace décadas con el encargo de la Declaración

Dr. Carlos Sánchez Avendaño. Universidad de Costa Rica. Profesor del Departamento de Lingüística. Organizador de la Segunda Semana de la Diversidad Lingüística de Costa Rica. Costa Rica.

Correo electrónico: tocumarama@yahoo.es

Recepción: 13- 11- 2013

Aceptación: 18- 03- 2014 
universal de los derechos lingüísticos, que en el artículo 30 encomienda: "La lengua y la cultura de cada comunidad lingüística deben ser objeto de estudio y de investigación a nivel universitario". Ciertamente nos faltará siempre mucho por hacer a este respecto, pero no podemos perder de vista que, en el contexto costarricense, sobresale el trabajo particularmente realizado en el Departamento de Lingüística de la Escuela de Filología, Lingüística y Literatura con respecto a las lenguas y variedades idiomáticas autóctonas del país.

El primer día nos sentíamos felices y orgullosos de abrir el evento con el homenaje al dedicado de esta edición: el Dr. Víctor Sánchez Corrales, profesor emérito de la Escuela de Filología, Lingüística y Literatura y fundador del programa Elexhicós (en el cual se elaboran diccionarios sobre el español de Costa Rica, diccionarios escolares y diccionarios de especialidad). Además de haber dedicado su vida académica principalmente al estudio del español de Costa Rica y a la lexicografía, don Víctor se ha ocupado del aporte que, desde la lingüística, se puede hacer al mejoramiento de la enseñanza del español en el sistema educativo público costarricense. Pese a haberse jubilado hace años, don Víctor se mantiene activo en la Universidad de Costa Rica, tanto en el programa Elexhicós como en la dirección de tesis, la organización del coloquio bienal sobre lexicografía y otras actividades académicas, como sus proyectos de investigación.

Sabíamos que el trabajo de don Víctor ha sido reconocido con diversos homenajes, como el haber sido nombrado miembro de número de la Academia Costarricense de la Lengua. Sin embargo, independientemente de la importancia de los múltiples reconocimientos que ha recibido y que sin duda seguirá recibiendo, estábamos convencidos de que siempre lo más bonito es que a uno lo agasajen en la propia casa. Por eso, a don Víctor le dedicamos esta segunda edición de la Semana de la diversidad lingüística de Costa Rica, que no pasa de ser un pequeño homenaje por tantos años dedicados a enseñar, investigar y llevar a cabo acción social en pro del mejor conocimiento de nuestras variedades de español y de su didáctica.

También ese primer día, procuramos destacar la amplia labor académica de don Adolfo Constenla Umaña. El conversatorio sobre su obra estuvo pensado como un homenaje por la totalidad de su trabajo dedicado a la documentación y descripción del patrimonio lingüístico costarricense, en particular el relativo a las lenguas indígenas del país y de la familia chibcha en general. Tristemente, don Adolfo, quien sufría una grave enfermedad desde hacía meses, murió en la noche del jueves 7 de noviembre, en plena Semana de la diversidad lingüística de Costa Rica. Tan lamentable suceso no fue óbice para que continuáramos con las actividades programadas para el día posterior, sabedores de que don Adolfo así lo hubiera querido. Continuar con la celebración de la diversidad linguiística de Costa Rica era la mejor forma de honrar su memoria.

Así, la organización de sendos conversatorios acerca de la obra de don Víctor y de don Adolfo fue nuestra forma de rendirles homenaje a quienes consideramos pilares de la lingüística en la Universidad de Costa Rica y en el país.

Finalmente, deseábamos mostrar de qué modo en la Escuela de Filología, Lingüística y Literatura intentamos continuar con la labor de estos dos grandes maestros mediante nuevas iniciativas. Por este motivo, aprovechamos el espacio para presentar algunos de los proyectos que hemos estado desarrollando en el TC-625 "Diversidad lingüística de Costa Rica”, en el cual, durante el año 2013, trabajamos con miembros de las comunidades malecu y bribri en microproyectos de documentación y creación artística, así como en el diseño de materiales didácticos para la enseñanza de sus lenguas autóctonas, con miras a fortalecer 
la colaboración encaminada a revitalizar, visibilizar, revalorizar, retener y promover su patrimonio lingüístico-cultural.

Los demás días los dedicaremos a cumplir nuestro segundo objetivo. Así, tuvimos actividades relativas a las lenguas indígenas de Costa Rica, las variedades del español costarricense, el inglés criollo limonense y la lengua de señas costarricense (LESCO).

Entre las actividades destacaron las conferencias de divulgación sobre estos idiomas y otras variedades idiomáticas que forman parte de nuestra historia (como el latín y el esperanto). Al igual que hacía dos años, nuestra consigna era que, en la medida de lo posible, los conferencistas redujeran el componente técnico en sus exposiciones y se dirigieran a un público amplio.

Asimismo, dada la magnífica acogida que tuvieron en la primera edición del evento, repetimos los talleres para aprender a presentarse en bribri y en LESCO, y sumamos dos más: uno para aprender a presentarse en brunca/boruca y otro para aprender malecu cantando y bailando.

También conservamos la figura de los conversatorios, otra de las actividades más provechosas de la primera edición. No obstante, esta vez la temática fue más variada. Además de los dos conversatorios ya aludidos sobre la obra académica de don Víctor y don Adolfo, invitamos a diversas personas conocedoras de cada tema a entablar una conversación sobre las necesidades de colaboración con las comunidades en lo que respecta al trabajo con su patrimonio lingüístico, el papel de la música en la revitalización y visibilización de la diversidad lingüística costarricense, y la perspectiva de los hablantes de lenguas minoritarias de Costa Rica en cuanto a sus derechos lingüísticos.

Finalmente, cerramos las actividades de tres de los días con actos culturales en los que la lengua fue el eje central. Así, nos deleitamos con poesía en inglés limonense, asistimos a la presentación de muestras de literatura en la lengua de señas costarricense, y clausuramos la Semana con un recital de música juvenil en malecu.

Como resulta obvio, un evento como este solo fue posible gracias a la ayuda desinteresada de muchas personas. Entre ellas, deseo destacar los nombres de los colegas y colaboradores de la Escuela de Filología, Lingüística y Literatura que participaron en alguna de las actividades: Antonio Leoni, Mario Hernández, Alberto Barahona, Carla Jara, Mario Portilla, Haakon Krohn, Henry Angulo, Henry Campos, Alí García, Annette Calvo y Jorge Murillo.

Del mismo modo, deseo agradecerles profundamente a otros colegas y amigos que desinteresadamente colaboraron en la organización o realización de este evento: Marielos Murillo, Carmen Rojas, Christian Ramírez, Daniela Sánchez, Miguel Ángel Quesada, Laura Cervantes, Giselle Ugalde, Karla Ramos, Yesenia Obando.

Y no podemos dejar de mencionar el nombre de los académicos pensionados de la Universidad de Costa Rica que nos honraron con su participación: don Hugo Mora y doña Flor Garita. Asimismo, es necesario reconocer y agradecer la enorme ayuda de muchas otras personas expertas y activas en lo que concierne al trabajo sobre el patrimonio lingüístico del país: Marcia Reid, Gabriela González, Franklin Perry, Isabel Quesada y Alexánder Hernández. También deseo destacar la colaboración de Radio U, de la Sección de TCU y de la Unidad de Audio de la Vicerrectoría de Acción Social.

Por último, la participación comprometida, responsable y propositiva de muchos de los estudiantes matriculados en el TC-625 resultó fundamental. Deseo mencionar en particular el nombre de aquellos que colaboraron activamente durante varios momentos: Alejandro Rocha 
Sánchez, Andrea Hidalgo Azuola, Esteban Gutiérrez Vargas, Gina Torres Calderón, Marco Soto Castro, Marijosé Chaverri Abarca, Raúl Leandro Fuentes, Rolando Salas Urrutia, Víctor Obregón Apéstegui y Yahaira Campos Morales. Asimismo, fue importantísima la labor de documentación videográfica que llevaron a cabo Cinthia Lara Pineda, Danny Chaves Gamboa, Margarita Morales Flores, Diego Moreira Ruiz y Valeria Fernández Sáenz. 